\title{
Defraudación tributaria y su incidencia en la sociedad
}

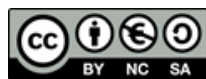

\section{Tax defraudation and its incidence in the company}

Fermín Andrés Haro Velastegui ${ }^{1}$, Mario Ruben Delgado Daquilema ${ }^{2}$, Guerrero Rivera Absalón Wilberto. ${ }^{3}$ \& Iván Patricio Arias González. ${ }^{4}$

Recibido: 28-04-2019 / Revisado: 25-05-209 /Aceptado: 28-06-2019/ Publicado: 30-07-2019

\begin{abstract}
.
DOI: https://doi.org/10.33262/cienciadigital.v3i3.2.749

Tax evasion is one of the problems, which can not be reduced within the business sector, due to legal limitations and ignorance of people to be able to comply with one of the obligations that the state has, since at the time of exercise any economic activity should be canceled taxes, which will vary depending on the economic activity of organizations and thus establish a relationship between informal sectors and tax evasion, to be able to establish their causes and consequences in order to improve the collection processes of the informal economy.
\end{abstract}

Keywords: Tax evasion, Informal sector

\section{Resumen.}

La evasión tributaria es uno de los problemas, que no se pueden reducir dentro del sector empresarial, debido por las limitaciones legales y el desconocimiento de las personas para poder cumplir con una de las obligaciones que se tiene con el estado, ya que al momento de ejercer cualquier actividad económica se debe cancelar los impuestos, los mismos que van a variar dependiendo la actividad económica de las

\footnotetext{
${ }^{1}$ Escuela Superior Politécnica de Chimborazo, Facultad de Administración de Empresas, Riobamba, Ecuador, fharo_velastegui@hotmail.com

${ }^{2}$ Universidad Nacional de Chimborazo, Facultad de Administración de Empresas, Riobamba, Ecuador, master_mdus@yahoo.com

${ }^{3}$ Universidad Estatal de Milagro, Facultad de Ciencias Sociales, Educación Comercial y Derecho, Milagro, Ecuador, aguerreror@unemi.edu.ec

${ }^{4}$ Universidad Nacional de Chimborazo, Facultad de Ciencias Políticas y Administrativas, Riobamba, Ecuador, ivan.arias@unach.edu.ec
} 
organizaciones y así poder establecer una relación entre los sectores informales y la evasión tributaria, para poder establecer sus causas y consecuencias con la finalidad de mejorar los procesos de recaudación de la economía informal.

Palabras claves: Evasión tributaria, Sector informal

\section{Introducción}

El comercio informal, se relaciona con los negocios que no se encuentran registrados dentro de la Administración Tributaria, ya que la ley establece que toda persona que ejerza actividad económica debe formalmente ser controlado y supervisado como sujeto pasivo, por lo que es uno de los sectores económicos más latentes para que se produzca la evasión tributaria, originando varios fenómenos dentro de la economía, por lo que se desconoce con exactitud su medición e incidencia en el sector económico.

Las actividades informales utilizan medios ilegales para cumplir los requisitos legales que establece el Servicio de Rentas Internas, ya que se considera informal a las actividades que no tienen un documento fuente de sustento, que evidencie el intercambio de la parte real por la parte financiera, debido a que un agente puede participar de manera formal en un mercado, pero de manera informal en otro.

Según (Andino, 2012) la evasión tributaria se refiere a la violación de la norma fiscal de hechos económicos, ocasionado de manera total o parcial el pago del tributo previsto por la ley, los mismos que van desde la disminución de valores obligados a pagar por el Estado hasta inflar los gastos permitidos como deducible por la normativa tributaria, ocasionado así la probabilidad de ser detectada para evitar las multas que impone la Administración Tributaria por no declarar sus actividades económicas en los tiempos establecidos por la misma.

Antes estos factores el contribuyente, toma la decisión de ser detectado al momento de no declarar las actividades económicas, para que la entidad recaudadora desconozca todo el manejo de la información y así decidir caer en la evasión tributaria (Ramírez, 2007).

El artículo 298 del Código Orgánico Integral Penal establece que: La persona que simule, oculte, omita, falsee o engañe en la determinación de la obligación tributaria, para dejar de pagar en todo o en parte los tributos, será sancionada con pena privativa de libertad de 1 a 10 años, dependiendo del tipo de defraudación tributaria cometido (Ministerio de Justicia, 2014, p. 113). 


\section{Metodología}

El método dialéctico es el fundamental para la fundamentación teórica de incidencia de la evasión tributaria en el sector informal, porque analiza el estudio de los tributos a través del método histórico se parte del análisis de la evolución de los tributos en el sector informal, por lo que se pretende determinar las causas acerca de la evasión tributaria en dicho sector para poder establecer mecanismos de control, que no perjudiquen la economía de dicho sector.

\section{Resultados}

Dentro del sector informal, se encuentran numerosos comercios populares, dedicados a la venta de alimentos, bazares, prendas de vestir, comidas entre otros, el mismo que se lleva a través del comercio de la calle, los llamados vendedores ambulantes, la misma que se caracteriza por falta de tecnología generando así productos simples de trabajo dentro de los cuales se puede mencionar como: costureras, carpinteros, zapateros, entre otros , la mayoría son de origen humilde que por falta de educación tributaria, desconocen los deberes formales que deben cumplir al momento de iniciar una actividad económica, ocasionando así un sistema tributario poco transparente debido a que existe un bajo riesgo de ser detectado

Por lo expuesto, (Hernando de Soto ,1994) expresa que el incumplimiento de las obligaciones directas y las leyes laborales es una de las diferencias, entre formales e informales; los empresarios formales pagan sus impuestos y lo hacen por ellos y por los que no pagan; los empresarios informales que evaden sus obligaciones tributarias producen como efecto que la carga tributaria se haga más pesada para aquellos que cumplen con sus impuestos.

Ante dichos factores, se considera necesario desarrollar una participación por parte de todos los sectores económicos, para establecer políticas tributarias y buscar un beneficio en conjunto (Rodríguez, 2014). Según (Robles, 2002) menciona que los ciudadanos deben concebir las obligaciones tributarias como un deber sustantivo, generando así un nivel de conciencia cívica al cumplimiento tributario, y disminuir el riesgo por el incumplimiento para poder disminuir los niveles de evasión existentes. (Méndez, Morales, \& Aguilera, 2005)

Por lo que se considera como un deber formal, por parte de todas las personas que ejerzan actividad económica, pagar impuestos los mismos que van a variar según el tipo de contribuyente, por eso debe concientizar para que la ciudadanía pueda conocer los beneficios que tiene al momento de pagar a tiempo sus impuestos y así puede evitar multas y sanciones por parte el Servicios de Rentas Internas.

El contribuyente decide cuándo evadir y qué importe evadir, en función tanto de los beneficios finales producto de la operación, como de la percepción del riesgo de ser descubierto por la Administración Tributaria con la consiguiente sanción. La evasión físcal 
consiste en sustraer la actividad al control fiscal y, por tanto, no pagar impuestos. Intenta reducir los costos tributarios, utilizando para ello medios ilícitos y vedados por las leyes, como el contrabando, fraude, etc. contra los que las autoridades deben luchar con todos sus medios legales para conseguir recuperar los ingresos perdido

El Código Tributario regula las relaciones jurídicas provenientes de los tributos entre los sujetos activos (Estado, Provincia, Municipio, etc.) y los contribuyentes o responsables de aquellos. Se aplica a todos los tributos: nacionales, provinciales, municipales, locales o de otros entes acreedores de los mismos, así como a las situaciones que se deriven o se relacionen con ellos. La ley de régimen tributario interno constituye la compilación de todo lo relativo en materia de impuestos, exenciones, deducciones, precios de transferencia, base imponible, contabilidad, estados financieros, retenciones, etc.

Por su parte, Sandmo (2004, pág. 4) señala sobre la evasión tributaria que se trata de una violación de la ley, consistente en que el contribuyente deja de declarar ingresos provenientes del trabajo o el capital, los cuales están en principio sujetos a tributación, involucrándose en una actividad ilegal que le hace responsable administrativa y legalmente ante las autoridades.

En contraposición a la elusión fiscal, el mismo autor comenta que cuando existe evasión fiscal, aunque al evasor le preocupa la posibilidad de que sus acciones sean detectadas, el potencial ahorro de impuestos hace que resulte interesante arriesgarse a ser detectado y sancionado por las autoridades.

La OECD (2014) señala que "Evasión es un término difícil de definir, que se utiliza generalmente para referirse a arreglos ilegales donde el cumplimiento de los impuestos resulta ocultado o ignorado la condición necesaria para la decisión de evadir vendrá dada por la desigualdad:

Beneficio esperado de la evasión > Coste esperado de la evasión

Donde, el valor esperado estará en función de la percepción subjetiva de la probabilidad de inspección y las sanciones aplicables. A su vez, la Administración Tributaria también analizará de forma similar la decisión de controlar la evasión solo si se cumple la condición.

Beneficio de la inspección > Coste de la inspección

Al respecto, Alm (1998, pág. 19) afirma que los aumentos en las tasas de penalización y la frecuencia de las inspecciones tributarias aumentan el cumplimiento tributario. Debido a que las tasas de penalización se ven a menudo como la herramienta preferida para reducir el fraude fiscal, ya que las sanciones pueden incrementarse por el simple cambio de una ley, mientras que los costes de comprobación tributaria requieren el compromiso de recursos adicionales por parte de la Administración Tributaria. 
En este contexto, se debe a que, por condiciones exógenas a la empresa, el negocio se torna cada vez más complejo en materia de precios, volumen de ventas, costes y movimientos bancarios, dejando un rastro de información que a menudo puede colocar al potencial evasor excesivamente expuesto al control de la Administración Tributaria. Difícilmente puede considerarse una cultura de cumplimiento voluntario si no existe una percepción de justo reparto de la carga tributaria y justa asignación de la recaudación (Roca, 2009, p. 51).

El art. 300 de la Constitución de la República declara que "El régimen tributario se regirá por los principios de generalidad, progresividad eficiencia, simplicidad administrativa, irretroactividad, equidad, transparencia y suficiencia recaudatoria". Lo señalado enfatiza que la política tributaria deberá promover la redistribución de bienes y servicios, así como conductas sociales y económicas responsables (Asamblea Nacional Constituyente, 2008, p. 55)

Por lo expuesto las principales obligaciones del contribuyente al momento de ejercer una actividad económica son: inscripción, presentación de declaración, veracidad y pago de impuesto, ante las cuales nacen las brechas del incumplimiento, ya que los contribuyentes teniendo la obligación de inscribirse no lo hacen o estando inscriptos no pagan de manera oportuna sus impuestos, generando así el pago incorrecto de sus obligaciones tributarias por lo que debe tenerse en cuenta que para mejorar la recaudación tributaria se deben cerrar las brechas del incumplimiento, porque no están inscritos en la Administración Tributaria, y se sitúan como informales.

Dentro de las principales causas de informalidad, podemos mencionar a las siguientes: La pobreza es uno de los factores del crecimiento de la economía informal

Actividades de inspección establecidas por los fedatarios del Servicio de Rentas Internas y del Municipio para que entreguen documentos que evidencien la actividad económica

La tecnología demanda personal altamente especializado, aislando así a personas no cualificadas que buscan trabajo en el sector informal

Por lo antes citado, el pago oportuno de los impuestos genera beneficios o tratos especiales a ciertos colectivos del sector económico, ocasionando así desmotivación a los contribuyentes, al ver que otros grupos poseen incentivos tributarios mientras ellos tienen que cumplir con la ley tributaria en todo su rigor. Las reformas tributarias casi siempre tienen como objetivo controlar de manera más efectiva y lograr mayores contribuciones de colectivos que de una u otra forma ya están controlados, mientras que, los pertenecientes a otros sectores más informales, ni siquiera son conocidos por la Administración Tributaria. 
Con respecto a la moral y ética tributarias, Llácer (2014, pp. 9 y 10 ) establece que debe existir una estrecha relación con la edad del contribuyente. Así, a mayor edad resultaría mayor moral fiscal, la misma relación se extiende también a la condición ocupacional del individuo, esto es, si es asalariado o trabajador autónomo. Los asalariados serían los que poseen un mayor grado de moral fiscal pues, al disponer de menores oportunidades para evadir, incurren en menor número de infracciones fiscales

Finalmente, Young y Saltiel (2011, pág. 29) establece que los pagos por impuestos tienen un importante impacto en la competitividad de las empresas, pudiendo ocasionar caídas en la productividad de las mismas. Menciona un principio básico de la tributación, que los tributos deben ser utilizados para recaudar recursos, y nunca deben ser utilizados para castigar a las personas, o para perseguirlas con fines políticos.

\section{Conclusiones}

- En base a la investigación analizada la cultura tributaria en nuestra sociedad no ha sido un factor determinante al momento de contribuir con el estado, por lo que origina las causas de la evasión tributaria por parte de las personas naturales, en el sector informal obligadas a llevar contabilidad, pues no se ha cumplido en un $100 \%$, de que dichos sujetos cumplan con la obligación en favor de estado, pues existe un gran índice de informales que no declaran sus impuestos en legal y debida forma.

- Un factor determínate ha sido la falta de capacitación y conocimiento de los contribuyentes a la hora de cumplir con la administración Tributaria, debemos indicar que ya mayor parte de personas que se dedican al comercio informal, no llevan una contabilidad adecuada, pues existe un alto índice de evasión tributaria, por su supuesto desconocimiento de como efectuar sus declaraciones.

- Por último, se puede establecer en base al resultado del análisis investigado el sector informal está obligado a llevar contabilidad, pues estos deben cumplir con la administración tributaria, para que no haya un perjuicio en contra del Estado.

- El sector informal, asociado al comercio ambulatorio y actividades de producción no registradas oficialmente, origina consecuencias negativas para el crecimiento económico de un país, siendo causa de la reducción de la base impositiva y evasión tributaria. Por qué se dedican de una manera completamente ilegal al desarrollo de actividades informales y no registran oficialmente sus ingresos, por consecuencia no los declaran, afectando la recaudación de tributos en nuestro país, perjudicando la caja fiscal estatal por no estar identificados como sujetos de una obligación formal, la investigación determina que el órgano de control a través de un sistema de control tributario adecuado, lograría prevenir prácticas nocivas para la convivencia social, como son: robo, lavado de dinero, tráfico de drogas, cohechos, etc.

- La Administración Tributaria, pretende generar un mayor control dentro del sector informal, para así poder contribuir a una mayor redistribución de los impuestos 
generando así una responsabilidad social en cada uno de los ciudadanos, a través de concientizar el beneficio de la cultura tributaria en cada una de las actividades económicas, los mismos que se encuentran relacionados con la ética y educación tributaria del mismo.

\section{Referencias bibliográficas.}

- Asamblea Nacional Constituyente (2008). Constitución de la República del Ecuador. QuitoEcuador: Registro oficial 449.

- Alm, J. (1998). Tax compliance and administration. Working Paper 98-12,1-60. Department of Economics, University of Colorado (Boulder, Colorado)

- Andino, M. (2012). Instrumentos y técnicas para medir la evasión. Obtenido de https://www.taxcompact.net/

- De Soto, H. (1994). ¿La economía informal futuro del tercer mundo? Revista Alternativas Económicas $\mathrm{N}^{\circ} 122$, Paris.

- Llácer, A. (2014). Factores explicativos de la evasión fiscal. Tesis doctoral, 1-328. (D. d. Psicología, Ed.- Barcelona). Universidad de Barcelona.

- Ministerio de Justicia, D. H. (2014). Código Orgánico Integral Penal. Quito- Ecuador: Subsecretaría de Desarrollo Normativo.

- Méndez, M., Morales, N., \& Aguilera, O. (2005). Cultura Tributaria y Contribuyentes: Datos y aspectos metodológicos. Fermentum. Revista Venezolana de Sociología y Antropología.

- Ramírez, J. (2007). Modelo de Equilibrio General Aplicado Tributario MEGAT. Quito, Ecuador: Servicio de Rentas Internas

- Rodríguez, J. (2014). Efectos de las Políticas Tributaria y Fiscalización sobre el tamaño del Sector Industrial en Colombia. Cuadernos de Economía.

- Robles, A. (2002). Cultura tributaria.

- Roca, J. (2009). Tributación directa en Ecuador. Evasión, equidad y desafíos de diseño. CEPAL, $85,83$.

- Sandmo, A. (2004). The theory of tax evasion: A retrospective view. Paper 31/04, 1-31. Norwegian School of Economics and Business Administration.

- OECD (2014). Centre for Tax Policy and Administration. Glossary of Tax Terms. Retrieved from: http://www.oecd.org/ctp/glossaryoftaxterms.htm

- Young, P., and Saltiel, M. (2011). The Revenue and Growth Effects of Britain's High Personal Taxes. 1-34. Adam Smith Institute. (C) Adam Smith Research Trust. Published in the UK by ASI (Research) Limited

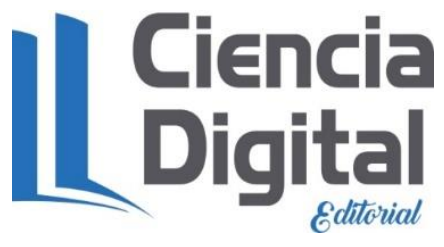




\section{PARA CITAR EL ARTÍCULO INDEXADO.}

Haro Velastegui, F., Delgado Daquilema, M., Absalón Wilberto, G., \& Arias González, I. (2019). Defraudación tributaria y su incidencia en la sociedad. Ciencia Digital, 3(3.2), 258-265. https://doi.org/10.33262/cienciadigital.v3i3.2.749

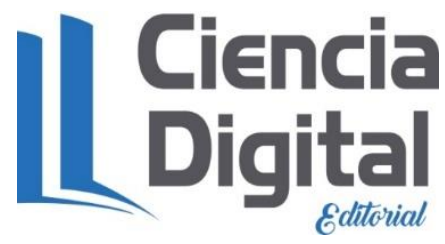

El artículo que se publica es de exclusiva responsabilidad de los autores y no necesariamente reflejan el pensamiento de la Revista Ciencia Digital.

El artículo queda en propiedad de la revista y, por tanto, su publicación parcial y/o total en otro medio tiene que ser autorizado por el director de la Revista Ciencia Digital.
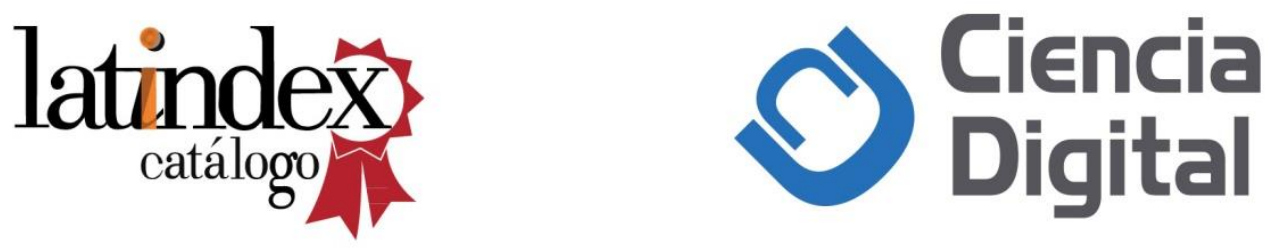